\title{
The Evaluation Culture to Build a Network of Competitive Cities in the Mediterranean
}

\author{
Stefano Aragona ${ }^{1, a}$, Francesco Calabrò ${ }^{1, b}$, Lucia Della Spina ${ }^{1, c}$ \\ ${ }^{1}$ Mediterranea University of Reggio Calabria. PAU - Department of Heritage, Architecture, Urban \\ Planning, Via Salita Melissari - 89124, Reggio di Calabria, Italy \\ astefano.aragona@gmail.com, brancesco.calabro@unirc.it, 'lucia.dellaspina@unirc.it
}

Keywords: Euro-Mediterranean Space. City Networks.

\begin{abstract}
The cities and urban areas are the engines for smart, sustainable and inclusive growth, that is, the places where you play the game of global competition between local development systems.

The role of cities in global competition brings with it a change of scale also in the system of relationships that the cities traditionally wove: this raises the need for their internationalization through the establishment of networks of transnational.

This paper presents a hypothesis for a network of cities of Mediterranean that the city of Reggio Calabria (Italy) could promote to improve its competitive capability.
\end{abstract}

\section{Introduction. The reference scenarios}

The gradual shift of the economic centre of gravity to the east, with the consequent marginalization of the majority parts of Europe, requires an approximation, in a short time, for the Mediterranean's peoples and their cultures to create a common space that will strengthen the interdependencies and complementarities [1].

This scenario becomes crucial to cities such as Reggio Calabria, whose special geographical location makes it imperative to look towards the Mediterranean but this does not imply it should ignore the strategic reference of Europe, and in particular to the program lines drawn for the Union's future, starting with the Europe 2020 Strategy.

In this sense, however, the substantial failure of the Euro-Mediterranean Partnership (EMP) resulting from the Barcelona Conference of 1995, that was aiming at the implementation of the Euro-Mediterranean Zone of Free Trade, gives an indication that a significant part of Europe is interested to develop exchanges with Eastern Europe rather than with the southern Mediterranean [2].

Nevertheless, the adoption in 2003 of the European Neighbourhood Policy (ENP) [3] is an initial step towards the direction for major attention to an Area of significant interest for Reggio's city.

\section{Territories and globalization}

Local communities, in the minor realities, relying on their ability to self-organization, must build pathways that are able to cope with, at the same time, to two different emergencies. First, do not be crushed by the transformations resulting from the logic of globalization that can mean processes of deterritorialization and/or only production of market values. Secondly, certainly related to the previous questions, the improvement of local living conditions.

They cannot leverage the competitive advantages of the main town, or city systems. The major urban centers associated in most institutions, Metrex, Eurocities, etc. have formulated strategies to achieve a balanced development of their territories, taking note of the choices within the EU in the first place the multimodal corridors and telecommunications networks.

It is very important detect $a$ delay that places the southern society/collectivity in rearguard positions on a national scale, moreover already as "national system" backward to the rest of the more advanced countries. Studies on the factors that determine the success and competitiveness - 
thanks to the creativity expressed by the various territories, based on the degree of Technology, Talent and Tolerance - see the cities of the South over the last places of the related ranking made for provinces. It is interesting to note that many small and medium cities mostly of the centre and north of Italy (such as. Rimini, Perugia, Modena, Padua, Pisa) are ranked in a good place by creativity, thus confirming the potential that also these territorial dimensions have. However it has to be remembered that they enjoy too of the benefits of being set in areas of influence of metropolitan areas. The closure of local systems is one of several factors that determine the result not brilliant of the South. Because the more an area is inaccessible to the exchange and to the diversity, the less is open to innovation and change. Turani points out that the percentage of acceptance of the gay population is one of the elements of analysis: the attitude towards this social subject is an indicator related to tolerance towards other cultures [4]. To have a widespread community [5] in which the individual is the center and the network, and in which the uncertainty and the consciousness of the limits of knowledge, of learning from error. Participating in the creation of the responsibilities of citizenship for the formation of the civitas [6], better if of urbs, the essential element is the willingness to listen and the reception of the outside.

After a short decentralization period the logic of urban hierarchy is reasserting itself. For two concurrent reasons that are becoming increasingly complementary: the policy choices, both at the national level and those at the local level and the pushes of market forces. State governments, in fact, in order to be able to compete on a global scale as a nation, are supporting their major centers while city governments increasingly seek to offer the cities as "integrated service", a privileged place for the location of assets and sales center, recreation and enjoyment of the present goods. In turn, the markets seen in the major centers privileged spaces thanks to the presence of denser, richer, demand. There are possible exceptions due to special conditions. So in the liberist North America Atlanta, although not among the top cities in the U.S. as population, however has particular conditions - there are the head offices of Coca Cola and CNN as well as having hosted the Olympics. Already years ago, indicators were developed to explain the discrepancy between the expected position on the bases of the central places theory and the effective one [7].

There is a risk that Calabria, in general the south after Naples, is excluded from the large traffic flows, infact it is proposing what Fusco has hypothesized as the "Mediterranean croissant" that goes from Valencia to the capital of the Campania region [8]. "The heart of the croissant is Catalonia, the regions of the South of France and the North-West Italian. By grouping the regions of Spain, French and Italian, among the richest and/or dynamics of the European Union, the croissant may create a system of the metropolitan centers of the Mediterranean coast (Barcelona, Marseilles, the conurbation French Riviera, Genoa, the binomial Pisa-Livorno) with those of its nearest interland (Zaragoza, Toulouse, Lyon, Turin, Milan, Bologna, Florence). Towards the south, the network would be extended up to Valencia and Alicante, Rome and Naples". A second "banana" which is the counterpart to the south of the "Blue Banana" and of the space of the "Pentagon", motor of Europe consisting by London, Amsterdam, Monaco, Zurich and Milan [9].

On "macro" level, the relationship between the metropolis of the croissant can only develop in a continuous dialectic of cooperation and competition. For each city, the insertion in a vast metropolitan reticular structure is the main element capable of ensuring visibility and competitive advantage internationally. However, it remains open the question of which metropolitan poles can connect over the network in a position of strength and benefit the most from the lattice structure. Moreover, experience shows that the connection is beneficial for the network as a whole but can be detrimental to the more weak urban realities of the system. The weakness, in turn, derives as much from inadequate size of the city (in terms of population and especially economic) as well as of its low degree of nodality in the network. Milan, for example, node of relationships between many cities of the croissant (Turin, Genoa, Bologna, Italy), as well as of relations with the axis of the development of the italian (North-East Verona, Venice) and the swiss and the rhenish areas, will be in a strong position compared to cities such as Toulon (simple place of passage of the coastal 
corridor between Marseille and the Cote d'Azur) or Naples (city connection terminal in the absence of further infrastructure developments towards Bari and Reggio Calabria).

Issue addressed and treated as early as 1993 when it was emphasized that with the option of socalled "cutting dead branches" of the railways associated with the creation of high speed (both still in progress) the result is "to approach who is far" and "turn away who is near", reinforce already strong urban poles, accentuate unbalanced development socially and environmentally. This choice of infrastructure policy is part of a liberistic philosophy and privatization of goods and services (post offices, pharmacies, etc.) until the recent past considered as "public goods". It is associated with so-called functional reorganization (e.g. the striking closure of many local judicial offices) based on criteria of microeconomics. All that is making transformations on "macro" scale and it is creating "competitive disadvantages" between areas (as already showed Goddard \& Gillespie in 1986 talking about telecommunications). In such a way those "minor" ones are destructured with the consequences of increasing the processes of their abandonment, raising the natural hazards (geological, etc.) and the congestion in the central towns (so disavowing the proclaimed sustainable development). If the choices that reinforce the concentration of population in the major urban centres are not changed, the metropolitan area of Reggio Calabria cannot formed. While the other areas, as part of a hypothetical network among Mediterranean centres, instead thanks to wider political strategies - that is multiple-criteria, i.e. not composed only by a microeconomics rationale they will be as important actors in the global competition. Basing their policies on the coexistence of the indispensable local identity and the "place based" rationale for the social economic development [10] with accessibility and functionality [11] not watching only at the Mediterranean basin, however privileged, but at entire world.

\section{The building of the network of cities for competitiveness}

The Europe 2020 Strategy [12] identifies the cities and urban areas as engines for smart, sustainable and inclusive growth. They are therefore the places where the required action to achieve its objectives and, therefore, to implement the strategy are mainly concentrated.

The condition that the cities can contribute to the implementation of the strategy is given by their competitiveness and attractiveness: in other words, the city will not automatically enjoy the benefits of the new dynamics triggered by the European strategy. These benefits will be reserved for those organizations that will be able to organize themselves as efficient systems, that is, in fact, competitive and attractive [13].

On the other hand, the cities' role in a global competition brings along a change of scale also in the system of relationships that the cities traditionally wove, placing the need for their internationalization through the establishment of transnational networks [14].

Cities must become the protagonists of a season of international relations aimed at negotiated search for innovative input-output, able to insert, "... in the current slowdown in the capitalist expansion, elements of a new sociality... promoting the transition from a market economy, which is functional neo-liberal globalization, towards a more complete democracy, such as possible construction of a new market socialism" [15].

\section{The culture of evaluation "tailor-made" for the construction of the Network}

The need to select the cities that respond effectively to the strategy must also be met through procedures that enable it to begin the process in good time: time, as a factor, is one of the main variables of competitiveness.

These requirements can find in the culture of the evaluation a valid scientific and operational support, necessary for the definition of strategies and policies for economic development [16].

To achieve effective evaluations it is not always necessary to resort to sophisticated models, but rather to pay attention to the purpose of evaluation, selecting the methods in relation to any specific assessment requests. 
The evaluation process, therefore, basically revolves around three issues [17]:

- The questions of which the evaluation must answer;

- The methods and procedures that the evaluation will use to answer questions;

- The nature of the relationship between the evaluator and the stakeholders.

In this case, a first selection can be made through the identification of a few easily verifiable criteria, consistent with the purpose of evaluation and shared by the stakeholders; the first hypothesis of selection will be then discussed with the stakeholders themselves in order to verify possible inconsistencies.

The evaluation procedure proposed is divided into five steps:

- Step 1: identification of evaluation criteria;

- Step 2: evaluation of the city-target, in relation to which the assessment is carried out;

- Step 3: evaluation of cities potential network nodes;

- Step 4: selection of cities-node;

- Step 5: verification of selection with stakeholders.

\section{The evaluation criteria}

The selection criteria must necessarily start from an examination of aspects like metropolitanisation and competitiveness for the cities, among all the factors generally listed in the literature [...] some can be considered conditioning factors, others conditioned. Some factors, such as the infrastructural facilities, in the short term, in fact, constitute a given that has effects on others, in this sense can be defined conditioning factors, while others, such as the productive system, are influenced from factors external to the system itself, such as the infrastructural facilities.

The conditioning factors to be considered may therefore be:

- Positional;

- Dimensional;

- Infrastructural;

- Research, Innovation, High Education.

\section{Size criterion}

Its easy to hypothesize that the dynamics of metropolitanisation will not be homogeneous in dimensionally very different realities: the dividing line, for example, can be provided by the European classification NUTS which, albeit for different logics, identifies a level 3 for the realities with population between 150,000 and 800,000 inhabitants, the level 2 for the reality between 800,000 and 3,000,000 and level 1 between 3,000,000 and 7,000,000.

\begin{tabular}{|c|c|c|}
\hline Class & Population Threshold Max & Population Threshold Min \\
\hline NUTS 1 & 7.000 .000 & 3.000 .000 \\
\hline NUTS 2 & 3.000 .000 & 800.000 \\
\hline NUTS 3 & 800.000 & 150.000 \\
\hline
\end{tabular}

\section{Infrastructural criterion}

The establishment of a network requires the possibility of a link between nodes. Beyond networks and intangible connections that modern technology allows, it becomes increasing significant that the physical connection between the territorial realities and the ability to guarantee fast and efficient movement of people and goods. In this sense, then, the selection of the network nodes will take place on the basis of their infrastructure: ports, airports, railways. 


\section{Criterion of Research, Innovation, High Education}

The central component of the Research, Innovation and Higher Education for competitiveness makes imperative that the network nodes are equipped with facilities of this type, which in turn will develop the synergies of the networks.

\section{The case study: Reggio Calabria and its network of cities for competitiveness.}

The acknowledgment of the status of Metropolitan City does not confer itself to Reggio Calabria either attractiveness or competitiveness: at the limit, can be a pre-condition for this to happen. The acquisition of these skills also involves the creation of a network of cities that will allow the necessary synergies to develop.

The results of the evaluation procedure described above, of course, may not be unique for all the organizations to which they apply: the city of Reggio Calabria has to select the nodes of a network functional to their needs, regaining its own planning capacity, that will allow the city to become again an active subject and not merely the executor of strategies designed elsewhere and functional to different situations [18].

The identification of nodes that will build the network can not be accidental, but rather functional to the objectives to be pursued: Experiences such as the ESI - European Network of the Straits, respond to different logics, absolutely partial and non-functional for the purposes described above.

In order to select the cities for which it's possible to network the factors of competitiveness, it is first necessary to evaluate, according to the four selection criteria, the city of Reggio Calabria, which is characterized by:

- the coastal location in the Mediterranean;

- the membership to the class NUTS 3,

- the presence of transport infrastructure such as Gioia Tauro port, airport, railway.

- the presence of research facilities and High Education such as: Mediterranea University, Dante Alighieri University, School of Public Administration, Centres and university research laboratories.

In the specific case of Reggio Calabria, then, attention should be paid to those cities for which there is in a state of obvious competitive disadvantage because of the positional factor: let's consider, for example, the ease relations between the cities located on the two sides of the Adriatic.

\section{The Network of Mediterranean cities.}

The evaluation of the cities overlooking the Mediterranean, on the basis of the criteria listed above, made it possible to identify, preliminarily, some potential nodes (Fig. 1):

- Tangier (Morocco),

- Oran (Algeria);

- Benghazi (Libya),

- Port Said (Egypt),

- Haifa (Israel),

- Tripoli (Lebanon),

- Latakia (Syria),

- Izmit (Turkey),

- Thessaloniki, Larissa, Volos (Greece),

- Toulon (France),

- Tarragona, Algeciras / Cádiz (Spain). 


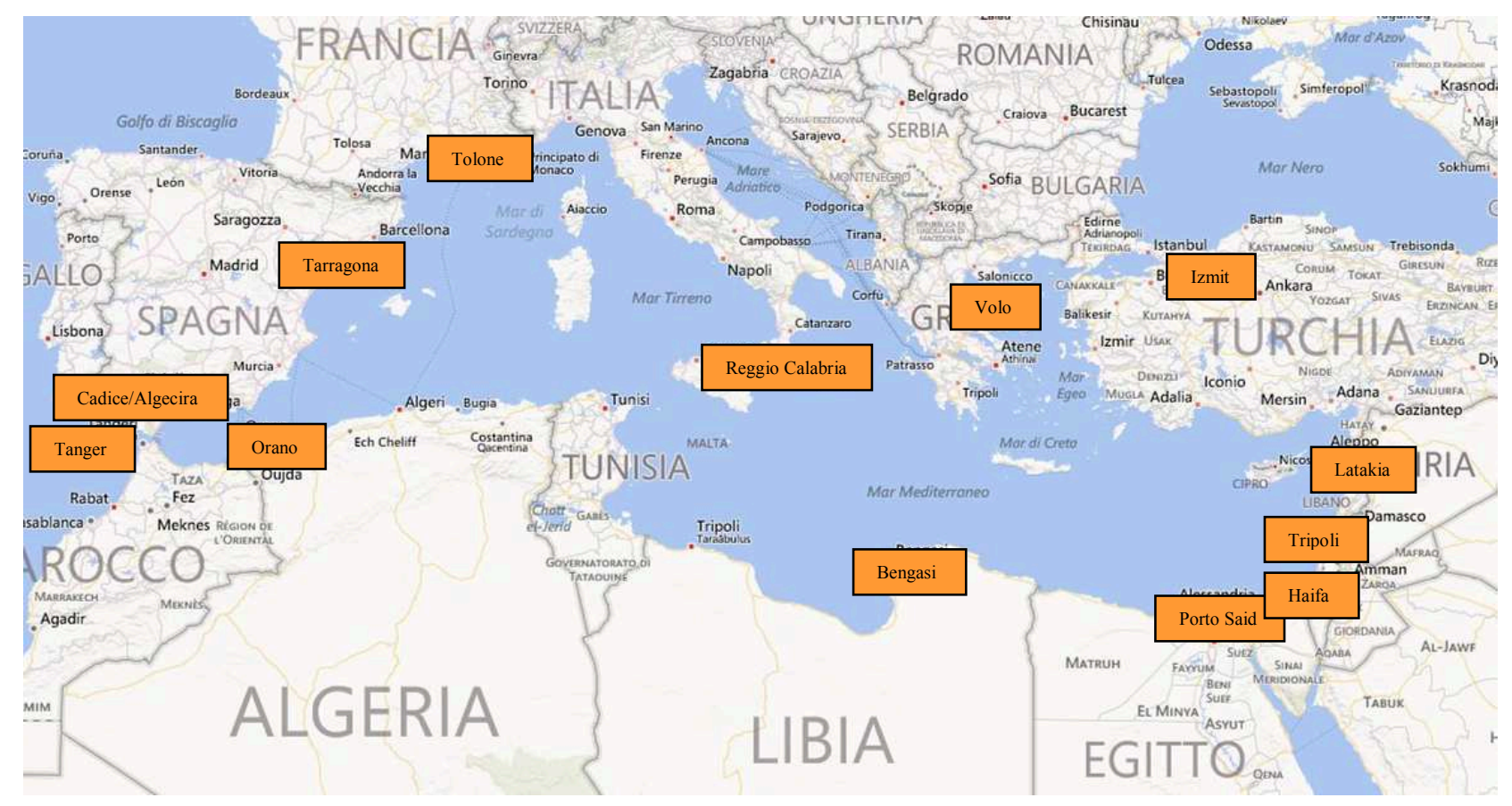

Fig. 1 - Identified potential nodes

\section{Conclusions.}

The results of the research are mostly partial; even the evaluation of potential city nodes of the network are incomplete and should be discussed with the main stakeholders, starting with the business system. Beyond the methodological insights, which may regarding, for example, the most properly evaluation aspects, it's however needed to timely start the phase of the results transfer: as pointed out by Edward Mollica in the editorial "La società delle culture, della ricerca, dei distretti industriali per uno spazio Euromediterraneo" (LaborEst n. 3/2009), the time factor is not indifferent to the competitiveness.

\section{References}

[1] E. Mollica: La società delle culture, della ricerca, dei distretti industriali per uno spazio euromediterraneo. LaborEst n. 3/2009, pag. 3. Laruffa. Reggio Calabria (2009)

[2] ISPI, Dossier: L'UE e i rapporti con la sponda sud. Information on: http://ispinews.ispionline. it. (2011)

[3] European Commission, European Neighbourhood Policy: Working towards a Stronger Partnership. Joint Communication to the European Parliament, the Council, The European Economic and Social Committee and the Committee of the Regions. Bruxelles (2013)

[4] G. Turani: Italia, il paese dei creativi poco istruiti, Affari e Finanza, 4 luglio (2005)

[5] E. Stagni: Un’idea di Comunità, FrancoAngeli, Milano (1998)

[6] M. Cacciari: Aut Civitas Aut Polis. In: Mucci E., Rizzoli P. (a cura di): L'immaginario tecnologico metropolitano, FrancoAngeli, Milano (1991)

[7] S. Aragona, Infrastrutture di comunicazione, trasformazioni urbane e pianificazione: opzioni di modelli territoriali o scelte di microeconomia? in Atti della XIV Conferenza Italiana di Scienze Regionali, vol.2, Bologna, (1993) 
[8] G. Fusco, Il "Croissant Mediterraneo": L'emergenza di una struttura reticolare macroregionale da Valencia a Napoli, in Atti della XXVI Conferenza Italiana di Scienze Regionali, Città e Regioni del Sud Europa. Trasformazioni, coesione, Sviluppo, Napoli. (2005)

[9] J. B. Goddard, A.E. Gillespie, "Advanced Telecommunications and Regional Economic Development", The Geographical Journal, 152, (1986)

[10] F. Barca, Un'Agenda per la Riforma della Politica di Coesione. Una politica di sviluppo rivolta ai luoghi per rispondere alle sfide e alle aspettative dell'Unione Europea. Rapporto indipendente predisposto nell'aprile 2009 per D. Hübner, Commissario europeo alla Politica Regionale, Sintesi e traduzione in italiano autorizzata dall'autore dell'Introduzione e dei capp. I e V del Rapporto An Agenda for a Reformed Cohesion Policy. (2010).

[11] S. Aragona, Tra la città forte e il territorio equilibrato: la seduzione ed il fascino delle infrastrutture, Atti del XXV Congresso I.N.U., Infrastrutture, città e territori, Roma 1,2 dicembre 2005 (2005)

[12] Commissione Europea, Europa 2020. Una strategia per una crescita intelligente, sostenibile e inclusiva. Comunicazione della Commissione COM (2010) 2020 del 3.3.2010. Bruxelles. (2010)

[13] E. Mollica: La ricerca scientifica, l'alta formazione, il globale e il locale. LaborEst n. 1/2008, pag. 3. Laruffa. Reggio Calabria (2008)

[14] B. Barber: If Mayors Ruled the World: Dysfunctional Nations, Rising Cities. New Haven (USA). Yale University Press (2013)

[15] E. Mollica: La società delle culture, della ricerca, dei distretti industriali per uno spazio euromediterraneo. LaborEst n. 3/2009, pag. 4. Laruffa. Reggio Calabria (2009)

[16] E. Mollica: La ricerca scientifica, l'alta formazione, il globale e il locale. LaborEst n. 1/2008, pag. 4. Laruffa. Reggio Calabria (2008)

[17] P. H. Rossi: H. Freeman, M. W. Lipsey, Evaluation, a Systematic Approach. Sage, Thousand Oaks, CA (1999)

[18] F. Calabrò, L. Della Spina: The cultural and environmental resources for sustainable development of rural areas in economically disadvantaged contexts. Economic-appraisals issues of a model of management for the valorisation of public assets. In: 3rd International Conference on Energy, Environment and Sustainable Development (ICEESD 2013). Advanced Materials Research Vols. 869-870, (2014), pp. 43-48 (C) (2014) Trans Tech Publications, Switzerland doi:10.4028/www.scientific.net/AMR.869-870.43, (2014)

[19] CENSIS: Rileggere i territori per dare identità e governo all'area vasta. Il governo delle aree metropolitane in Europa. Report di ricerca (2014)

[20] F. Cassano: Tre modi di vedere il sud. Bologna. Il Mulino (2009) 